\title{
XX Brazilian Symposium of Electrochemistry and Electroanalysis (SIBEE_Simpósio Brasileiro de Eletroquímica e Eletroanalítica) at Uberlândia, Minas Gerais, Brazil
}

\author{
Artur J. Motheo ${ }^{1}$
}

Received: 12 October 2015 / Accepted: 15 October 2015 / Published online: 23 October 2015

(C) Springer-Verlag Berlin Heidelberg 2015

The Brazilian Symposium of Electrochemistry and Electroanalysis (SIBEE) is the most important national forum to discuss the advances and challenges of electrochemistry and electroanalytical chemistry and especially for dissemination of scientific and technological results. The history of SIBEE began in São Paulo, at the Chemistry Institute of the University of São Paulo, 12-14 October 1978. This first edition of SIBEE, organized by Prof. Eduardo Fausto de Almeida Neves and Prof. Tibor Rabóczkay, had 28 oral presentations and 46 participants, among them are researchers from Argentina, led by Prof. Alejandro Jorge Arvia from the Instituto de Investigaciones Fisicoquímicas Teóricas y Aplicadas (INIFTA).

The following editions of SIBEE took place every 2 years with the number of participants increasing, reflecting the steady maturing of the scientific community involved in research on electrochemical and electroanalytical chemistry. However, the initial feature established by the founders remained, i.e., to prioritize the quality and accuracy of the discussions of the works presented, seeking to bring scientists of recognized competence to deliver lectures and discuss science at the highest level.

Thus, this special issue is to celebrate the consolidation of an idea and the realization of the XX Brazilian

Artur J. Motheo

artur@iqsc.usp.br

São Carlos Institute of Chemistry, University of São Paulo, SP 13566-590 São Paulo, Brazil
Symposium of Electrochemistry and Electroanalysis (SIBEE) in August 2015 in the city of Uberlândia, Minas Gerais, Brazil. On that occasion, 570 communications (oral and poster), 47 keynotes, and 8 plenary were presented, bringing together 792 participants and covering virtually all sub-areas of electrochemistry. It was a high standard scientific meeting that gave to all participants an excellent atmosphere to discuss electrochemistry, to meet people, and to interchange experiences. It also represented a special occasion when it was founded the Brazilian Society of Electrochemistry and Electroanalysis (Sociedade Brasileira de Eletroquímica e Eletroanalítica).

At this opportunity, I would like to thank the organizing committee coordinated by Prof. João Marcos Madurro from the Federal University of Uberlândia, Minas Gerais, and all the speakers, particularly those with researchers recognized expertise in electrochemistry that presented the plenary lectures: Prof. Ana Maria Oliveira Brett (University of Coimbra, Portugal), Prof. Lauro Tatsuo Kubota (University of Campinas, Brazil), Prof. Nenad M. Markovic (Argonne National Laboratory, USA), Prof. Romeu Cardozo Rocha Filho (Federal University of São Carlos, Brazil), Prof. Shelley D. Minteer (University of Utah, USA), Prof. Susana Inês Cordoba Torresi (University of São Paulo, Brazil), Prof. Tim Burstein (University of Cambridge, England), and Prof. Wolfgang Schuhmann (Ruhr-Universität Bochum, Germany).

Special thanks should be made to Professor Fritz Scholz, editor-in-chief of the Journal of Solid State Electrochemistry, for welcoming the proposal of a special issue and for all the support received by the editorial board. 